\title{
Avaliação de aspectos Formais EM QUATRO PERIÓdicos CIENTÍFICOS NA ÁREA DE EDUCAÇÃO ESPECIAL
}

ASSESSMENT OF FORMAL ASPECTS IN FOUR PERIODICALS IN THE FIELD OF

SPECIAL EDUCATION

\author{
Maria Cristina Piumbato Innocentini HAYASHI ${ }^{1}$ \\ Carlos Roberto Massao HAYASHI ${ }^{2}$ \\ Maycke Young de LIMA ${ }^{3}$ \\ Márcia Regina da SILVA ${ }^{4}$ \\ Érica Aparecida GARRUTTI ${ }^{5}$
}

\begin{abstract}
RESUMO: a avaliação do periódico é de fundamental importância para medirmos a qualidade das pesquisas, assim como sua confiabilidade e rigor. O objetivo deste artigo é identificar os aspectos formais a serem aperfeiçoados e os aspectos que já se adequam às formalidades do universo das publicações científicas com base na aplicação de uma metodologia para análise de periódicos que possibilita a identificação destes aspectos formais da publicação. Foram avaliadas quatro publicações da área de Educação Especial, quais sejam, Benjamin Constant, Revista Brasileira de Educação Especial, Revista Educação Especial e Espaço em relação aos aspectos formais de um periódico. Conclui-se que os periódicos analisados já atingiram alguns quesitos, mas ainda precisam adequar-se a outros devidamente descritos no trabalho.
\end{abstract}

PALAVRAS-CHAVE: educação especial; produção científica; periódicos; ciência da informação.

\begin{abstract}
: assessment of a given periodical is basic to measuring the quality of research, as well as its reliability and seriousness. The objective of this article is to identify formal aspects to be improved and aspects that are already adequate to the formality required of the universe of scientific publications; to this end, an analysis methodology was applied to the periodicals to enable the identification of formal aspects of the publication. Four publications from the field of Special Education were evaluated, those being, Benjamin Constant, Revista Brasileira de Educação Especial, Revista Educação Especial and Espaço, in relation to the formal aspects of each periodical. The conclusions showed that the periodicals analyzed have already achieved some criteria, but there is still work to be done if they are to achieve all criteria described in the work.
\end{abstract}

KEYWORDS: special education; scientific production; periodicals; information science.

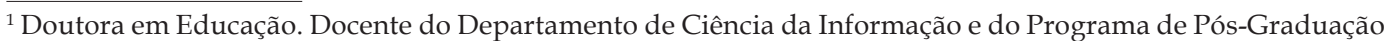
em Educação Especial da UFSCar - Universidade Federal de São Carlos - Centro de Educação e Ciências Humanas -dmch@power.ufscar.br

${ }^{2}$ Doutorando no Programa de Pós-Graduação em Educação da UFSCar. Docente do Departamento de Ciência da Informação da UFSCar - massao@power.ufscar.br

${ }^{3}$ Graduando em Biblioteconomia e Ciência da Informação da UFSCar. Bolsista de iniciação científica da FAPESP - maycke@gmail.com

${ }^{4}$ Doutoranda no Programa de Pós-Graduação em Educação da UFSCar. Bibliotecária na USP-Ribeirão Preto marciaregina@usp.br

${ }^{5}$ Mestranda no Programa de Pós-Graduação em Educação Especial da UFSCar - egarrutti@yahoo.com.br
} 


\section{INTRODUÇÃo}

No mundo da produção científica, o reconhecimento de uma publicação, seja ela um livro, tese, dissertação, periódico, etc pode ser avaliada, em grande parte, pelos indicadores de qualidade e credibilidade das publicações científicas. Assim, a avaliação das publicações científicas é de fundamental importância para estimarmos a qualidade das pesquisas, assim como para o alcance da confiabilidade da publicação, como salientam Silva (2004) e Yamamoto (2001). É nesse contexto que se insere o presente trabalho, que tem por objetivo realizar uma análise dos aspectos formais da comunicação científica na área de Educação Especial no Brasil.

\section{Periódicos científicos: aspectos conceituais e metodologias de avaliação}

Foi no século XVII, logo após o início da ciência experimental, que apareceram os primeiros periódicos científicos. Os cientistas perceberam que o meio de comunicação até então utilizado para divulgar os resultados de suas pesquisas - representado pela troca de correspondências - já não se mostrava adequado para a disseminação das novas descobertas científicas. Em 1665, aparecem simultaneamente na França e na Inglaterra, as primeiras revistas científicas: o Journal des Sçavants (ou Journal des Savants, conforme grafia atualizada no começo do século XIX) e o Philosophical Transactions of the Royal Society of London, ambos ligados às sociedades científicas da época: a Académie Royale des Sciences de Paris e a Royal Society of London, conforme assinala Hayashi (2004).

Para Campello e Campos (1993) o periódico científico possui três funções: a de registro público do conhecimento, pois qualquer indivíduo pode oferecer à apreciação um trabalho para publicação e, também, pode obter a publicação; a função social, isto é, o periódico atribui prestígio e reconhecimento tanto aos autores, quanto aos editores, aos referees e, inclusive aos seus assinantes; e a função de disseminação da informação, pois coloca a informação à disposição do leitor, uma vez que se ela não for publicada, não existe. Miranda e Pereira (1996) também ressaltaram que o periódico científico como veículo de comunicação do conhecimento, cumpre funções de registro oficial público da informação mediante a reconstituição de um sistema de editor-avaliador e de um arquivo público, fonte para o saber científico.

Neste contexto, a estreita relação entre comunicação e pesquisa científica, ressaltada por Mayor (1996) ao afirmar que "a ciência não é nada se ela não se comunica" pode ser ampliada quando recordamos com Ziman (1979) de que ciência é conhecimento público e argumentamos como Meadows (1999), de que a comunicação situa-se no próprio coração da ciência, uma vez que ciência só se legitima quando é analisada e aceita pelos pares por meio de um processo tornado possível com a publicação. Sendo assim, o que confirma a existência da pesquisa e torna seus resultados importantes é a comunicação científica. 
Opinião semelhante é compartilhada por Valério (2005) ao discorrer sobre as funções de um periódico científico. A autora menciona que a primeira delas é a de disseminação do conhecimento, uma vez que a publicação de artigos originais resultantes da pesquisa científica constitui a primeira informação que inicia o diálogo científico. Para a autora, ao publicar, o periódico científico fornece elementos para a recuperação da informação, por meio dos títulos, sumários e resumos os quais permitem o acesso e a recuperação de artigos, autores e dos próprios títulos de periódicos. A função de registro também é destacada por Valério (2005), a qual confere a propriedade intelectual ao autor, ou a prioridade de autoria. Esta função permite realizar o processo de controle de qualidade do artigo por meio da aplicação do sistema de peer review (revisão por pares) e troca de informações entre editor e avaliadores, tendo em vista a verificação da veracidade, originalidade, importância e qualidade dos artigos submetidos à aplicação. Além destas, a autora ainda menciona outras duas funções do periódico científico: a de memória, uma vez que fornece um arquivo que se constitui em memória e fonte histórica para o conhecimento e a função de instituição social, por atribuir prestígio e reconhecimento a autores, instituições, editores e avaliadores, sendo que esta função também desempenha um importante papel na definição e legitimação de novos campos do conhecimento.

Ao refletir sobre o papel que é atribuído ao periódico científico na construção da ciência, Mueller (1999) discute alguns dos problemas específicos dos periódicos científicos publicados pelos países que não estão na fronteira do desenvolvimento da ciência, ao mesmo tempo em que também questiona a função dos periódicos destes países - entre os quais se inclui o periódico científico brasileiro.

A autora destaca que o periódico científico tem sido objeto de muitos estudos, motivados pelo papel que representa na construção do conhecimento científico. Disto decorre que, geralmente são atribuídas quatro funções ao periódico científico: a) estabelecimento da ciência "certificada", ou seja, do conhecimento que recebeu o aval da comunidade científica; b) canal de comunicação entre os cientistas; c) divulgação mais ampla da ciência, arquivo ou memória científica; d) registro da autoria da descoberta científica. Além disto, essas funções não se alteraram, a despeito das transformações recentes nos meios de comunicação (MUELLER, 1999).

Ao relacionar os estudos já realizados sobre os periódicos científicos Mueller (1999) destaca os seguintes tipos: a) aqueles que relatam o aparecimento e o desenvolvimento do periódico científico como meio de comunicação científica, ou focalizam o periódico em contraposição a outros meios de comunicação científica; b) aqueles que se interessam pela sua avaliação, tendo como premissa a sua representatividade da ciência e como unidade de estudo os próprios periódicos, os autores, o artigo, as citações ou referência bibliográficas aos seus artigos ou por eles referidas, o uso registrado nas bibliotecas ou serviços de acesso, ou a opinião de usuários sobre eles, sendo que estes estudos são geralmente realizados tendo como base títulos específicos e identificados. 
Segundo Barbalho (2005) é necessário compreender os elementos e critérios que regem, validam e qualificam uma publicação periódica científica, a partir da premissa de que o volume de informações circulantes no mundo de hoje é infinitamente grande. Para a autora, este fato gera problemas para monitorar e controlar a produção, tendo em vista uma premência de se estabelecer um padrão de qualidade compatível com as exigências de produção do conhecimento útil ao desenvolvimento científico, tecnológico e social dos países. Deste modo, não basta publicar: é fundamental que o material produzido seja localizado, lido e aceito, ou seja, avaliado.

Para que um periódico possa sobressair na massa de publicações produzidas que cresce a cada ano e consolidar-se de forma reconhecida pela comunidade acadêmica é necessário a utilização de instrumentos de avaliação. Com estes subsídios a comunidade acadêmica poderá identificar os periódicos científicos que melhor sirvam aos seus interesses, ou seja, determinar os critérios que permitam estabelecer indicadores de qualidade a estes periódicos.

Os estudos sobre a avaliação dos padrões de qualidade de periódicos científicos enfocam essencialmente os aspectos intrínsecos e extrínsecos, relacionados à forma (desempenho) e ao conteúdo (mérito), conforme relatam Valério (1991, 1994), Miranda e Pereira (1996) e Stumpf $(1998,2003)$.

Instituições internacionais, regionais e nacionais, conforme relata Stumpf (2003), desde a década de 1960, desenvolvem programas de avaliação de revistas com diferentes abordagens e metodologias, entre elas a Organização das Nações Unidas para a Educação, Ciência e Cultura (UNESCO), o Centro LatinoAmericano e do Caribe de Informação em Ciências da Saúde (BIREME), a Fundação de Apoio à Pesquisa do Estado de São Paulo (FAPESP), o Conselho Nacional de Desenvolvimento Científico e Tecnológico (CNPq), a Financiadora de Estudos e Projetos (FINEP) e a Coordenadoria de Aperfeiçoamento de Pessoal de Nível Superior (CAPES).

Qualquer revisão de literatura que se faça sobre a avaliação de periódicos no país deve passar, necessariamente por estudos que se tornaram referência na área, entre eles os de Braga e Oberhofer (1982) - considerado por Trzesniak (2006a) como sendo o primeiro artigo a respeito da avaliação formal de periódicos científicos brasileiros - em que as autoras traçam diretrizes para avaliação de periódicos científicos inspiradas nas diretrizes estabelecidas em 1962 pela UNESCO, conforme relata Bonini (2004). O modelo de avaliação proposto pelas autoras apresenta sete critérios: normalização, duração, periodicidade, indexação, difusão, colaboração e divisão de conteúdo e autoridade. De acordo com estes critérios o periódico é classificado como de desempenho fraco, mediano, bom ou muito bom.

Schwartzman (1984) também sugeriu os seguintes padrões de qualidade para as publicações científicas brasileiras: a) reputação, que pode ser traduzida pelo gabarito de seu corpo de editores, pela seriedade e imparcialidade de seus processos 
de seleção de trabalhos para publicação; b) padronização e regularidade, pois as revistas científicas, para terem divulgação adequada, necessitam adotar os padrões editoriais consagrados internacionalmente e ser publicadas de forma regular e previsível. Para o autor, são estes fatores, combinados com o anterior, que permitem que elas sejam indexadas nas fontes de referência existentes em várias partes do mundo e subscritas de forma regular por bibliotecas, centros de pesquisa e pesquisadores individuais. c) eficiência no relacionamento com autores, leitores e assinantes, fundamental para garantir às revistas o interesse dos colaboradores e leitores, sem o qual elas não conseguem manter seus padrões de qualidade e prestígio. d) apresentação gráfica - uma vez que a tendência universal parece ser no sentido de processos de impressão cada vez mais rápidos e simples, desde que fique garantida a clareza dos textos e ilustrações, assim como sua correção. Schwartzman (1984) destaca ainda que os critérios mais gerais de qualidade, e que devem condicionar qualquer apoio público a revistas científicas, são o seu prestígio nacional e internacional, a qualidade e representatividade de seus colaboradores, a sua padronização, regularidade, e circulação.

Por sua vez, os periódicos científicos apoiados pelo programa do $\mathrm{CNPq}$ e FINEP foram avaliados por Oliveira (1989) e Valério (1991, 1994) em estudos que apontaram a importância do cumprimento de exigências relacionada aos aspectos formais e de conteúdo dos periódicos para garantir seus padrões de qualidade.

Além destes estudos a literatura científica sobre avaliação dos periódicos científicos é bastante ampla e no âmbito latino-americano podem ser destacados os trabalhos de Castro, Ferreira e Vidilli (1996), López-Cózar (1997), Krzyzanowski e Ferreira (1998), Pessanha (1998), Rodrigues, Lima e Oliveira-Garcia (1998), RíosOrtega (2000), Gomes e Santos (2001), Yamamoto et al. (2002), Yamamoto, Souza e Yamamoto (1999), Ferreira e Krzyzanowski (2003), Alonso-Gamboa (2003), Bomfá (2003), Bomfá et al. (2006), Souza, Vidotti e Foresti (2004), Barbalho (2005), Gruszinski e Sanseverino (2005), López-Ornelas, Cordero-Arroyo e Backhoff-Escudero (2005), Oliveira (2005), Schultze (2005), Souza (2006), Gruszynski e Golin (2006), Fachin, Hillesheim e Rados (2005, 2006) e Trzesniak (2006a, 2006b).

López-Cózar (1997) ao avaliar o grau de ajuste das revistas espanholas de ciências da saúde às normas internacionais de apresentação de publicações periódicas, refere que a normalização das publicações científicas é um elemento importante no êxito da comunicação e especialmente no processo de transferência da informação científica, uma vez que facilita o trabalho dos agentes do circuito de comunicação primária - autores, editores, impressores e leitores - e secundária: bibliotecários, gerentes de centros e sistemas de informação. Além disto, o autor argumenta que a normalização incide na difusão das revistas já que condiciona a sua presença em bases de dados e determina a qualidade dos estudos bibliométricos, o que repercute na avaliação da ciência.

Ainda no âmbito da normalização científica, Rodrigues, Lima e OliveiraGarcia (1998) apontaram que esta é fator de eficiência na transferência da 
informação, ao mostrar que estudos em vários campos do conhecimento indicaram a qualidade formal como fator determinante para aceitação ou rejeição de trabalhos para publicação, o que amplia o valor da normalização na comunicação científica.

Ríos-Ortega (2000) também apontou a necessidade de incremento nos estudos de normalização das revistas científicas mexicanas tendo em vista os benefícios que poderiam advir no sentido de fortalecer os processos de transferência de informação e para a comunicação científica daquele país.

No que diz respeito à avaliação de periódicos científicos por áreas de conhecimento, inúmeros trabalhos têm sido desenvolvidos, entre outros os de Marcuschi (2001), na área de Lingüística; Gomes e Santos (2001) na área de Medicina Tropical; Pinheiro et al. (2005) na área de Ciência da Informação; Amorim et al. (2005) na área de Odontologia; e nas áreas da Saúde, da Comunicação e da Educação os estudos mais recentes são os de Pereira (2006), Romancini (2004), Dias (2006) e Trzesniak (2006b).

Souza, Gauer e Hutz (2004), Soares et al. (2006), Costa (2006) e Jacon (2006) também avaliaram periódicos científicos da área de Psicologia sendo que o primeiro estudo baseou-se em dois periódicos científicos da área de Psicologia do Desenvolvimento; o segundo analisou a Psicologia divulgada em periódicos científicos indexados. O estudo de Costa (2006) focalizou os paradoxos da classificação Qualis em Psicologia, realizada pela Capes, com base em uma metaavaliação sobre o processo de avaliação de periódicos científicos utilizado nas revistas de Psicologia. Jacon (2006) também verificou se a base Qualis, uma vez implementada, induziu o uso dos periódicos nela melhor classificados, elegendose como objeto de estudo os periódicos Qualis da área de Psicologia e como contexto o Programa de Pós-Graduação da PUCCAMP.

Entre os estudos de avaliação de periódicos científicos na área de Psicologia destaca-se aquele realizado por Yamamoto, Souza e Yamamoto (1999) com base em uma demanda da Coordenação de Aperfeiçoamento de Pessoal de Nível Superior (CAPES), utilizando o modelo de avaliação proposto por Krzyzanowski e Ferreira (1998) que foi modificado para o propósito da pesquisa. Este estudo teve continuidade (YAMAMOTO et al., 2002), mas, desta feita, os instrumentos para avaliação dos periódicos foram uma Ficha de Avaliação com escala total (avaliação de qualidade A, B e C) e uma sub-escala para classificação de âmbito (nacional ou internacional) do periódico. A escala total foi composta de cinco tópicos gerais: normalização, publicação, circulação, autoria e conteúdo; gestão editorial, com pontuação de 0 a 20 para cada tópico, para um total máximo de 100. A sub-escala de âmbito constava de 5 sub-itens: indexação, distribuição, disponibilidade em bibliotecas do sistema nacional, abrangência geográfica dos autores e dos conselhos editoriais.

Ao examinar a literatura sobre o tema Alonso-Gamboa (2003) menciona que há dois aspectos a serem considerados quando se avalia um periódico científico: os critérios de qualidade da revista como um todo, no qual intervém de maneira 
importante a observação e o cumprimento das normas nacionais e internacionais para sua apresentação além de aspectos relacionados à gestão editorial e também a análise de conteúdo da revista, que indaga sobre a qualidade e estrutura das contribuições. Como já mencionamos, Valério $(1991,1994)$ denomina estes indicadores de qualidade de extrínsecos (relacionados aos aspectos formais da revista) e intrínsecos, como aqueles que têm a ver com a qualidade do conteúdo (visibilidade, difusão nacional e internacional e citações recebidas).

Stumpf (2003) refere que as metodologias quantitativas de avaliação de periódicos - que têm como princípio a avaliação de mérito pelos pares, mediante parâmetros pré-definidos pelos responsáveis pela avaliação - têm sido bastante utilizadas no país e no exterior. A autora ressalta ainda que a utilização de indicadores de conteúdo (mérito) e forma (desempenho) das revistas científicas nem sempre fica clara nos estudos realizados, embora a literatura internacional tenha dedicado maior atenção ao processo de avaliação dos originais pelos pares, por considerar que o controle de qualidade dos periódicos é fundamental para a manutenção do elevado padrão de qualidade da ciência. Os parâmetros para avaliação do conteúdo dos periódicos, segundo Stumpf (2003), subdividem-se em diretos e indiretos, sendo que os primeiros referem-se à qualidade de conteúdo dos artigos que os periódicos publicam e os indiretos dizem respeito à reputação do periódico em relação à idoneidade da instituição publicadora, à amplitude e abrangência da composição do conselho editorial ou científico, ao sistema de seleção de originais, origem institucional ou procedência dos autores, difusão geral ou circulação da revista, indexação por serviços bibliográficos nacionais ou internacionais, medidas de citações e fator de impacto.

Com relação aos critérios de qualidade extrínsecos ou formais dos periódicos científicos Stumpf (2003) afirma que vários itens podem ser investigados e a rigidez dos parâmetros adotados depende da área que se está analisando. A autora relaciona, entre outros, os seguintes aspectos a serem analisados com relação aos aspectos formais das revistas científicas: periodicidade, regularidade da publicação, respeito às normas de apresentação (padronização aceita nacional e/ ou internacionalmente), duração (refletindo tradição e continuidade), tiragem, quantidade média de artigos que recebe e publica em cada fascículo, bem como a correta apresentação gráfica.

Por sua vez, Fachin, Hillesheim e Rados (2005) mencionam que os periódicos científicos, quando padronizados e normalizados, "asseguram aspectos como: informações atualizadas, conhecimento de pontos de vista distintos sobre um mesmo tema, aprofundamento de pesquisas e investigações e como elemento fundamental na preservação do conhecimento, sua difusão relativamente rápida e o estabelecimento da prioridade científica, por atuar mais como veículo de reconhecimento científico de seus autores e editores". A autora argumenta que a padronização dos periódicos científicos possibilita sua indexação em base de dados referenciais, em sua área de conhecimento ao mesmo tempo em que "promove os professores e alunos que publicam e fazem parte de comissões editoriais, bem 
como, os demais autores e editores, permitindo maior acesso à informação com qualidade e rapidez".

Fachin, Hillesheim e Rados (2006) apresentaram estudos realizados sobre a padronização de periódicos científicos, discutindo a questão da avaliação de originais. Destaca a importância do uso de normas e padrões e das comissões editorais para o reconhecimento e a eficácia dos periódicos científicos, como disseminador do conhecimento.

Mais recentemente, ao apresentar requisitos de qualidade para os periódicos em papel e eletrônicos, sugerindo procedimentos práticos para sua avaliação, Trzesniak (2006a) acrescentou mais duas dimensões a serem consideradas na avaliação de periódicos científicos: a de percepção do mercado e a do processo de produção.

Ao discorrer sobre a avaliação de periódicos científicos Trzesniak (2006b) menciona que também pesquisadores-editores vêm atuando na avaliação de periódicos para agências de fomento, relativamente à concessão de financiamento. Na visão do autor, ao lado destes, há outra frente de avaliadores de periódicos científicos: a dos indexadores. O artigo de Trzesniak (2006b) destaca o papel destes dois tipos de atores: o pesquisador de certa área ou profissional de Biblioteconomia e de Ciência da Informação que atuam na avaliação de periódicos científicos, e o modo como trabalham nos diversos momentos e para as diferentes finalidades (publicação, busca de informação, recomendação para aquisição, julgamento de projetos de pesquisa e de concursos, inclusão em indexadores, concessão de financiamento, e construção de hierarquias ou rankings.

Esta revisão de literatura sobre os aspectos conceituais e as metodologias de avaliação de periódicos teve o propósito de fundamentar a pesquisa realizada do ponto de vista teórico e metodológico. Como vimos, as abordagens sobre a avaliação dos periódicos científicos são variadas e os modelos propostos adotam diferentes critérios. Em termos gerais, os periódicos científicos nacionais procuram se adequar a estes modelos sendo que alguns dos critérios foram incorporados pelos mais importantes sistemas de avaliação de periódicos no país, quais sejam o Scielo e o Qualis Capes que estabelecem os seus próprios critérios, políticas e procedimentos para a admissão e permanência de periódicos científicos em sua coleção e lista, respectivamente.

\section{DESCRIÇÃo Do MÉTOdo dE ANÁLISE}

Stumpf (2003) ao refletir sobre os indicadores avaliação de avaliação de periódicos científicos refere que o planejamento de um estudo deste tipo requer a seleção das seguintes opções: quais revistas avaliar, o quê nelas avaliar (critérios), a quem avaliar (sujeitos) e como avaliar (metodologia).

Seguindo os passos desta autora, descrevemos a seguir os caminhos percorridos na pesquisa realizada sobre os aspectos formais dos periódicos científicos em Educação Especial, ou seja: 
a) quais revistas avaliar - foram selecionados para análise quatro periódicos de renome na área de Educação Especial no país, sendo dois deles de caráter científico e dois de caráter técnico-científico, quais sejam: Revista Brasileira de Educação Especial (RBEE); Revista Educação Especial (REE); Benjamin Constant e Espaço: informativo técnico-científico do INES. Essa seleção foi baseada em consultas a bases de dados nacionais e internacionais, além de outros procedimentos que fizeram parte de projeto de pesquisa ${ }^{6}$ que originou este artigo e de resultados parciais relatados por Hayashi et al. (2006).

b) quem avalia - com respeito a quem iria avaliar os periódicos, os próprios autores do estudo funcionaram como avaliadores, uma vez que o estudo não objetivou ouvir os produtores de conhecimento - os referees das revistas e os pesquisadores da área, ou seja, aqueles que mais convivem com a bibliografia da área e que são também os que selecionam os veículos mais adequados para registrar e divulgar sua produção, segundo Stumpf (2003) - e sim avaliar os critérios extrínsecos dos periódicos em questão.

c) o quê avaliar - conforme exposto na fundamentação teórica deste estudo, a avaliação de periódicos científicos pode ser de diferentes tipos de acordo com o tipo de avaliação que se quer proceder. No presente estudo a avaliação ancorou-se em critérios de qualidade extrínsecos ou formais (de desempenho) dos periódicos, conforme preconizado por Stumpf (2003), quais sejam: periodicidade, regularidade da publicação, respeito às normas de apresentação (padronização aceita nacional e/ou internacionalmente), duração (refletindo tradição e continuidade), tiragem, quantidade média de artigos que recebe e publica em cada fascículo, bem como a correta apresentação gráfica e o modelo de Bomfá (2003) de análise de periódicos no todo referente a critérios de normalização, instrução aos autores e avaliação dos artigos. Neste aspecto a pesquisa foi realizada com a aplicação de ferramentas de análise oriundas da Ciência da Informação, não se prendendo aos aspectos da temática abordada pelos artigos ou da avaliação destes quando submetidos ao periódico - o que já foi abordado por Manzini na Revista Brasileira de Educação Especial (RBEE) respectivamente em seus artigos de 2003 e 2004 publicados nesse mesmo periódico, os quais podem assegurar sua disseminação e confiabilidade. Deve-se acrescentar também que, segundo Bomfá (2003, p.63), “as características formais dos periódicos científicos são de grande relevância para sua aceitabilidade pela comunidade nacional e internacional".

d) como avaliar - a pesquisa realizada caracteriza-se como exploratória e descritiva e a metodologia adotada consistiu na aplicação parcial de um modelo de avaliação desenvolvido por Bomfá (2003); parcial, porque o modelo completo possibilita também a análise dos artigos, o que, conforme especificado anteriormente, não é a pretensão do presente estudo. A adoção

${ }^{6}$ Projeto "CCN e Educação Especial", desenvolvido pelos autores e patrocinado pelo CNPq. Vigência: 2005-2006. 
do modelo de Bomfá (2003) deve-se ao fato de que, apesar da existência de outros modelos de avaliação quanto aos critérios de desempenho de periódicos científicos este nos pareceu ser o mais adequado aos propósitos da pesquisa proposta, por ser mais atual e incorporar a maioria dos itens dos modelos anteriores.

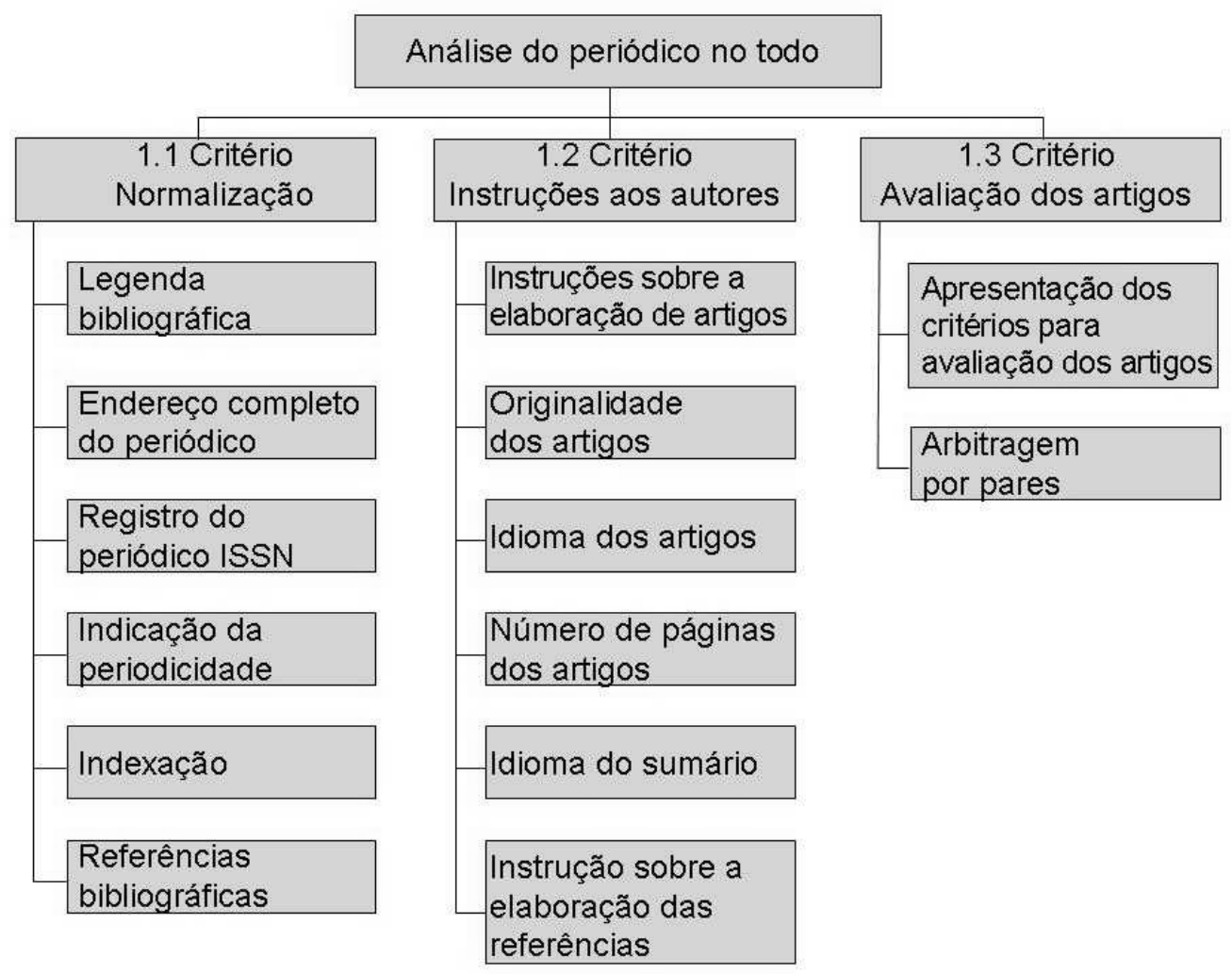

Figura 1 - Organograma da análise do periódico no todo.

A seguir, apresentamos os periódicos selecionados para análise, com uma breve descrição de seus objetivos, vinculação institucional e escopo editorial, elaborada com base na consulta aos próprios periódicos:

Benjamin Constant - publicação periódica de responsabilidade do Centro de Pesquisa, Documentação e Informação do Instituto Benjamin Constant IBCENTRO, vinculado à Divisão de Documentação e Informação do Departamento Técnico-Especializado desta Instituição. O objetivo desta publicação técnicocientífica é o fomentar e o desenvolver ações voltadas para o atendimento às pessoas portadoras de deficiência visual, visando atingir professores, educadores, reabilitadores e familiares de deficientes visuais. Em 2005 o periódico completou 10 anos de existência, contribuindo para a disseminação da informação sobre deficiência visual e sobre o próprio instituto ao qual pertence esta publicação, 
além da divulgação de várias outras iniciativas e recursos didáticos para a educação especial nesse contexto.

Para a pesquisa foi consultado o exemplar impresso do número 31, ano 11, de agosto de 2005 e as demais edições no site < http:/ / www.ibc.gov.br/>.

Revista Brasileira de Educação Especial - publicação periódica de responsabilidade da ABPEE - Associação Brasileira de Pesquisadores em Educação Especial - em parceria com a Faculdade de Filosofia e Ciências da Unesp em Marília, agora no SCIELO. O objetivo desta publicação é dar suporte ao intercâmbio de informações técnico-científicas em Educação Especial e áreas afins. São publicados artigos originais, principalmente, de pesquisas, porém, abrindo espaço para ensaios, artigos de revisão e resenhas. Em 2005, até o volume 11, número 2, o periódico contava com 144 artigos publicados, além das resenhas, comentários e informes.

Foram consultados 17 exemplares impressos do periódico, a partir do volume 1, número 1, publicado em 1992, até o volume 11, número 2, referente ao intervalo maio-agosto de 2005.

Revista Educação Especial - publicação periódica de responsabilidade do Departamento de Educação Especial do Centro de Educação da Universidade Federal de Santa Maria (UFSM). O objetivo desta publicação é o de veicular estudos, pesquisas e experiências na área para ampliação do horizonte e aprofundamento de temas concernentes à Educação Especial. Conhecida inicialmente como "Cadernos de Educação Especial", título modificado em 2004, sua publicação iniciou-se em 1987. E no intervalo analisado (2000-2005), o periódico conta com 121 textos publicados.

Foi consultado o exemplar impresso do periódico referente ao número 24, de 2004 e as demais edições no site <http:/ / www.ufsm.br/ce/revista/>.

Espaço: informativo técnico-científico do INES - publicação periódica que, como o próprio nome diz, é de responsabilidade do INES - Instituto Nacional de Educação de Surdos. O objetivo desta publicação é dar suporte ao intercâmbio de informações técnico-científicas em Educação Especial e áreas afins. O periódico é dividido em várias seções que abordam aspectos diversificados na área de surdez, quais sejam: Espaço Aberto; Debate; Atualidades em Educação; Reflexões sobre a prática; Produção Acadêmica; Resenhas de livros; Material técnico-pedagógico e Visitando o acervo do INES. Considerando os números pesquisados, o periódico apresenta 68 artigos publicados, além dos outros conteúdos.

Foram consultados oito números do periódico, todos digitalizados como se segue: números 21 e 22 e edição comemorativa, digitalizadas integralmente em PDF (com capa, contracapa, etc); número 20 - somente textos digitalizados em PDF (em um só arquivo); números 17, 18 e 19 - divididos por espaço de publicação na página HTML, com links para os respectivos textos digitalizados em PDF; número 16 - divididos por espaço de publicação na página HTML, com links para os respectivos textos digitalizados também em HTML, no site <http:/ / www.ines.org.br/>. 
Portanto, os critérios que poderiam ser analisados somente com o periódico impresso foram avaliados de acordo com os exemplares obtidos, o que veio ao encontro da recomendação de Stumpf (2003) ao assinalar que alguns critérios de avaliação de periódicos científicos exigem a presença física do periódico no momento da avaliação.

Os critérios presentes no organograma (Figura 1) foram adaptados para aplicação nos periódicos em questão, conforme mostra sua descrição a seguir.

\subsection{CRITÉRIO NORMALIZAÇÃo}

Buscou-se verificar se as informações estavam facilmente visíveis ao leitor, visto que um periódico, além de disseminar a informação, deve apresentála sob um padrão estipulado. $O$ padrão utilizado como base para elaboração desta metodologia foram as normas da Associação Brasileira de Normas Técnicas (ABNT).

Legenda bibliográfica: Verificou-se neste critério a presença da legenda bibliográfica em rodapé, na folha de rosto e em cada página dos artigos constando dos seguintes elementos: título do periódico, local de publicação, número do volume e do fascículo, paginação e data.

Endereço completo do periódico: Considerou-se a indicação do endereço completo - nome da instituição, endereço para contato, telefone e fax - registrado de forma a facilitar a visualização da informação.

Registro do periódico - ISSN: O ISSN (International Standard Serials Number) é um código adotado internacionalmente para publicações seriadas. Levou-se em consideração se o periódico apresentava ISSN.

Indicação de periodicidade: Indicação da freqüência de publicação dos números. Observou-se se o periódico analisado cumpria a periodicidade adotada.

Indexação: Verificou-se se o periódico estava indexado em alguma base de dados nacional ou internacional.

Normalização das referências bibliográficas: Verificou-se qual o sistema de normas adotado pela revista e se o padrão adotado estava, de fato, sendo seguido.

\subsection{CRitério inSTRUÇÕES AOS AUTORES}

Instruções sobre a elaboração dos artigos: Trata-se do espaço reservado, geralmente no final do periódico, para a apresentação das normas referentes ao texto e às referências bibliográficas para os autores. Devem constar critérios referentes ao envio dos artigos, idioma, formatação, conteúdo e a norma adotada para elaboração das referências bibliográficas. Verificou-se a presença e a clareza dessas instruções.

Originalidade dos artigos: Observou-se a presença de exigências quanto à originalidade dos artigos, ou trabalhos já publicados em outros periódicos ou congressos. 
Idioma dos artigos: Analisou-se a especificação de idioma para elaboração dos trabalhos.

Número de páginas do artigo: Verificou-se a indicação de um limite de páginas para os trabalhos encaminhados. Isto é de extrema importância, visto que orienta claramente o autor quanto à extensão do artigo.

Idioma do Sumário: A NBR-6027 define sumário como a listagem das partes do periódico na mesma ordem que aparecem na publicação. Foi verificada, além presença de um sumário, uma versão deste em outro idioma, visto que é um dos critérios para indexação em várias bases de dados.

Instruções sobre a elaboração das referências: Este é um critério de suma importância, visto que possibilita o acesso às fontes originais de pesquisa aos interessados. Verificou-se a presença deste critério no periódico, preferencialmente com exemplos, o que agrega valor em relação ao conteúdo informacional das instruções.

\subsection{CRitério AVAliaÇão dos ARTigos}

Apresentação dos critérios para avaliação dos artigos: Buscou-se identificar se os critérios para avaliação dos artigos submetidos encontravam-se expressos no periódico de forma clara aos autores.

Arbitragem por pares: Observou-se se os trabalhos submetidos são avaliados por mais de um avaliador.

\section{Resultados e discussão}

As análises referentes a Benjamin Constant, a Revista Brasileira de Educação Especial, a Revista Educação Especial e a revista Espaço foram realizadas respectivamente em novembro de 2005, janeiro, fevereiro e março de 2006. Algumas dificuldades foram encontradas durante a análise de três periódicos, quais sejam:

Benjamin Constant: no número 14, de outubro de 1999, os artigos não estão disponíveis na íntegra online, constam somente os títulos e os respectivos autores; o número 30, de abril de 2005, não está disponível online, sendo consultada apenas sua capa através da edição impressa do número 31, que traz em sua capa uma imagem reduzida de todas as capas dos números anteriores.

Revista Educação Especial: o intervalo do número 1 ao número 14 não está disponível online, fato que ocasionou uma limitação da análise aos números disponíveis virtualmente mais o único exemplar (24) disponível em forma impressa.

Espaço: informativo técnico-científico do INES: o intervalo do número 1 ao número 15 não está disponível online, fato que ocasionou uma limitação da análise aos números disponíveis virtualmente.

O Quadro 1 busca facilitar o entendimento dos resultados obtidos a partir da análise dos periódicos, fornecendo informações gerais de forma a 
proporcionar uma ampla visualização das características observadas com a aplicação da metodologia. Posteriormente estão descritos todos os critérios individualmente, com as respectivas considerações.

Quadro 1 - Resultados da avaliação dos periódicos.

\begin{tabular}{|c|c|c|c|c|}
\hline $\begin{array}{l}\text { CRITÉRIOS DE } \\
\text { AVALIACC ÃO }\end{array}$ & $\begin{array}{l}\text { BENJAM IN } \\
\text { CONSTANT }\end{array}$ & RBEE & $\begin{array}{l}\text { REVISTA } \\
\text { EDUCACC A O } \\
\text { ESPECIAL }\end{array}$ & ESPAC O \\
\hline 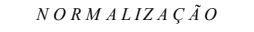 & Norm as A B N T & Norm as A B N T & Norm as A B N T & Norm as A B N T \\
\hline Legenda bibliográfica & Regularizada $(*)$ & Regularizada & Regularizada $(*)$ & Regularizada \\
\hline $\begin{array}{c}\text { Endereço completo do } \\
\text { periódico }\end{array}$ & Apresenta & Apresenta & Apresenta & Apresenta $(* *)$ \\
\hline $\begin{array}{c}\text { Registro do periódico- } \\
\text { ISSN }\end{array}$ & Apresenta & Apresenta & Apresenta & Apresenta \\
\hline $\begin{array}{l}\text { Indicação da } \\
\text { periodicidade }\end{array}$ & $\begin{array}{c}\text { Quadrimestral- } \\
\text { regularizada a partir } \\
\text { doano6, n. 15, de } \\
\text { abr. } / 2000\end{array}$ & $\begin{array}{c}\text { Quadrimestral - a } \\
\text { partir do volume } 10 \\
\text { n. } 1 \text {, de jan.- } \\
\text { abr. } / 2004\end{array}$ & $\begin{array}{l}\text { Semestral (não } \\
\text { indicada } \\
\text { explicitamente) }\end{array}$ & Semestral \\
\hline Indexação & Não indexado & $\begin{array}{c}\text { BEE/Inep; } \\
\text { EDUBAS } \\
\text { (FE/UNICAMP); } \\
\text { CLASE (México, } \\
\text { UNAM); Psicodoc } \\
\text { (Espanha) }\end{array}$ & $\begin{array}{l}\text { B EE/Inepe } \\
\operatorname{LATINDEX}\left({ }^{*}\right)\end{array}$ & Não indexado \\
\hline $\begin{array}{c}\text { Normalização das } \\
\text { referências } \\
\text { bibliográficas }\end{array}$ & $\begin{array}{l}\text { ABNT }(*) \text {; seguido } \\
\text { com maior rigor a } \\
\text { partirde } 2002\end{array}$ & $\begin{array}{l}\text { A BNT deago. } / 2000 ; \\
\text { seguidocom maior } \\
\text { rigora partirde } 2000\end{array}$ & $\begin{array}{l}\text { ABNTNBR } 6023 / \\
\text { ago./2002; seguido } \\
\text { com maior rigora } \\
\text { partirde } 2005\end{array}$ & $\begin{array}{l}\text { ABNT NBR } 6023 / \\
\text { de ago./2002; não é } \\
\text { seguido devidamente }\end{array}$ \\
\hline $\begin{array}{c}\text { INSTRUCOOESAOS } \\
\text { AUTORES }\end{array}$ & $\begin{array}{l}\text { No final do } \\
\text { periódico }\left({ }^{*}\right)\end{array}$ & No final do periódico & $\begin{array}{l}\text { No final do } \\
\text { periódico }(*)\end{array}$ & $\begin{array}{c}\text { No final do } \\
\text { periódico }(* *)\end{array}$ \\
\hline $\begin{array}{c}\text { Instruções sobre a } \\
\text { elaboração dos artigos }\end{array}$ & $\begin{array}{c}\text { Orientação para } \\
\text { apresentação dos } \\
\text { artigos }\end{array}$ & $\begin{array}{c}\text { Orientação para } \\
\text { apresentação dos } \\
\text { artigos }\end{array}$ & $\begin{array}{c}\text { Orientação para } \\
\text { apresentação dos } \\
\text { artigos }\end{array}$ & $\begin{array}{c}\text { Orientação para } \\
\text { apresentaça dos } \\
\text { artigos }(* *)\end{array}$ \\
\hline $\begin{array}{c}\text { Originalidade dos } \\
\text { artigos }\end{array}$ & $\begin{array}{l}\text { Trabalhos inéditos, } \\
\text { ou publicados em } \\
\text { periódicos } \\
\text { estrangeiros }\end{array}$ & Trabalhos inéditos & Trabalhos inéditos & $\begin{array}{c}\text { Não é necessário ser } \\
\text { inédito, desde que } \\
\text { exista a autorização } \\
\text { do editorda } \\
\text { publicacáo } \\
\text { prévia(**) }\end{array}$ \\
\hline Idiom a dos artigos & $\mathrm{Não}$ mencionado & $\begin{array}{l}\text { Preferencialmente } \\
\text { em português }\end{array}$ & \begin{tabular}{|l} 
Português, espanhol, \\
francês, ing lês, \\
alemão ou italiano \\
\end{tabular} & $\begin{array}{l}\text { Português ou } \\
\text { espanhol }(* *)\end{array}$ \\
\hline $\begin{array}{c}\text { Número de página dos } \\
\text { artigos }\end{array}$ & Fixa 10 páginas & Fixa 25 laudas & $\begin{array}{c}\text { Estipula um intervalo } \\
\text { de númerode } \\
\text { palavras }\end{array}$ & Fixa 6 páginas \\
\hline Idiom a do Sumário & Português & Português e inglês & Português e inglês & Português $(* *)$ \\
\hline $\begin{array}{c}\text { Instruções sobre a } \\
\text { elaboração das } \\
\text { referências }\end{array}$ & $\begin{array}{c}\text { Normas ABNT, sem } \\
\text { exemplos }\end{array}$ & $\begin{array}{c}\text { Normas ABNT, com } \\
\text { exemplos }\end{array}$ & $\begin{array}{c}\text { Normas ABNT, sem } \\
\text { exemplos }\end{array}$ & $\begin{array}{c}\text { NBR-6023 (a partir } \\
\text { do n. 22), sem } \\
\text { exemplos }(* *) \\
\end{array}$ \\
\hline $\begin{array}{c}\text { AVALIACEAOO DOS } \\
\text { ARTIGOS }\end{array}$ & $\cdots$ & No final do periódico & No final do periódico & $\ldots$ \\
\hline $\begin{array}{l}\text { Apresentação dos } \\
\text { critérios para avaliação } \\
\text { dos artigos }\end{array}$ & Nãomencionados & Mencionados & Mencionados & $\mathrm{Não}$ mencionados \\
\hline Arbitragem porpares & $\begin{array}{l}\text { Comissão editorial } \\
\text { composta de } \\
\text { professores e } \\
\text { técnicosdaáreade }\end{array}$ & $\begin{array}{c}\text { Os trabalhos são } \\
\text { submetidosa } 2 \\
\text { pareceristas e, } \\
\text { Quando necessário, }\end{array}$ & $\begin{array}{c}\text { Os trabalhos são } \\
\text { submetidos a } 2 \\
\text { pareceristas e, } \\
\text { quando necessário, a }\end{array}$ & $\begin{array}{l}\text { Os trabalhos são } \\
\text { revisados pela } \\
\text { Comissão Editorial }\end{array}$ \\
\hline
\end{tabular}

(*) Dados obtidos somente a partir de apenas um exemplar impresso, já que essas informações não puderam ser obtidas através das edições online. ${ }^{* *}$ Conferidos apenas nos exemplares digitalizados integralmente.

Considerando o Critério Normalização, foi encontrado um padrão em todas as publicações. Cada periódico apresenta um projeto gráfico padrão individual, sendo que o periódico Benjamin Constant apresenta várias seções além daquela de artigos, tais como "Palavra Final", "Relato", entre outras, que enriquecem o periódico com várias outras abordagens não necessariamente científicas, o que proporciona o caráter técnico da revista, além de ser um canal permanente para divulgação de informações relativas ao Instituto Benjamin Constant (IBC). 
O periódico Espaço apresenta os mesmos atributos que proporcionam o caráter técnico da publicação, constituindo também um canal para divulgação de informações relativas ao Instituto Nacional de Educação de Surdos (INES); a RBEE sofreu uma modificação considerável em seu projeto gráfico no número 5 de 1999 e outras alterações propostas pelo CNPq, no volume 8, número 2 de 2002, fascículo a partir do qual o periódico mantém o projeto gráfico sem demais alterações.

A Revista Educação Especial sofreu uma modificação em seu projeto gráfico juntamente com a adoção de um novo título para o periódico a partir do número 23 de 2004. Quanto à legenda bibliográfica todos os periódicos apresentamse regularizados, mas vale salientar que o periódico Benjamin Constant apresenta a legenda apenas no rodapé da seção de artigos e na página de rosto e os periódicos Espaço e Revista Educação Especial não apresentam o número do volume, já que não o adota, e por isso não seria possível indicá-lo.

O endereço completo situa-se na contracapa e na página de rosto da Benjamin Constant; na RBEE ele está localizado na página de rosto até o número 4 de 1996, a partir do número 5 de 1999 encontra-se no verso da página de rosto do periódico e nas instruções para envio de artigos; na Revista Educação Especial situase no verso da página de rosto e na última página do periódico, após as instruções de envio de trabalhos, facilitando a visualização da informação; e na Espaço situase na página de rosto e no editorial do periódico. Todas apresentam o nome da instituição, endereço para contato, telefone, e e-mail, além disso, o primeiro e os 2 últimos periódicos ainda apresentam o número de fax.

Constatou-se o registro do International Standard Serials Number (ISSN) para todos os periódicos, posto que, na Benjamin Constant situa-se na capa, a partir do número 7 , além de ser também encontrado na ficha catalográfica e na página de rosto do periódico; vale salientar que os dois últimos locais especificados foram conferidos apenas no exemplar do periódico impresso em mãos - número 31, de agosto de 2005. Na RBEE ele se situa, a partir do número 5, na capa, na ficha catalográfica e na contracapa do periódico; na Revista Educação Especial encontrase na página de rosto e na ficha catalográfica; e na Espaço está, a partir do número 21, na capa, página de rosto, editorial e ficha catalográfica do periódico.

De acordo com Bomfá (2003, p.74), a "periodicidade é fator importante no que tange a confiabilidade do periódico, visto que o cumprimento da freqüência (publicação estipulada) encoraja os autores a enviarem seus artigos, atestando a disseminação da pesquisa científica". A periodicidade indicada na página de rosto da Benjamin Constant é quadrimestral - verificado na versão impressa disponível e é cumprida rigorosamente a partir do ano 6, número 15, de abril de 2000. Além disso, foi publicada uma edição especial em setembro de 2004, sem artigos e dedicada exclusivamente a contar a história do IBC.

$A$ RBEE, no decorrer dos 17 fascículos observados, tende à estabilização em 8 artigos por fascículo. Um fato curioso deve ser mencionado aqui é que, de 
1992 a 1999, a numeração atribuída aos fascículos passou a ser referida como volume em trabalhos publicados sobre o periódico (MANZINI, 2003, 2004), ou seja, os números de 1 a 5 são hoje referidos como volumes de 1 a 5 nos trabalhos publicados, e essa numeração é adotada formalmente pelo periódico a partir do volume posterior (6) publicado em 2000.

A periodicidade indicada no verso da página de rosto e na ficha catalográfica do periódico é quadrimestral e é cumprida rigorosamente a partir do volume 10, número 1, de janeiro-abril de 2004, fascículo no qual entrou em vigor. Vale salientar que antes disso, a periodicidade indicada era semestral e fora cumprida apenas no intervalo que vai do volume 7 de 2001 ao volume 9 de 2003. Foram observadas duas interrupções da $R B E E$, fato também mencionado por Manzini (2003, p.15): “A primeira em 1993 e a segunda no período de 1997 e 1998, estas interrupções não são abordadas no editorial do volume 2 e volume 5, que foram subseqüentes às interrupções".

A periodicidade semestral, não indicada no periódico explicitamente, é seguida rigorosamente desde o primeiro número analisado. Dois fatos curiosos constatados na análise deste título são: na ficha catalográfica do periódico é mencionada a palavra "irregular", que se deduz tratar da periodicidade, porém, conforme exposto, ela está bem regularizada; e na última página é mencionado que a assinatura anual dá direito a dois exemplares, de onde se deduz a periodicidade semestral, devidamente seguida.

A da periodicidade para a revista Espaço, no decorrer dos 8 fascículos observados, tende à estabilização em 9 artigos por fascículo. A periodicidade indicada na ficha catalográfica dos números 21 e 22 do periódico é semestral e é cumprida a partir do número 16, de julho-dezembro de 2001.

Quanto ao quesito de indexação, observou-se que a Benjamin Constant e a Espaço são as únicas que não se encontram indexadas em base alguma, porém elas constam na Lista Qualis, que Manzini (2003, p.16) explica sucintamente: “No Brasil, a Capes encomenda uma avaliação para as entidades, como a Associação Nacional de Pós-Graduação e Pesquisa em Educação (ANPED) e Associação Nacional de Pesquisa e Pós-Graduação em Psicologia (ANPEPP) dentre outras, classificarem os periódicos. Essa classificação foi denominada como Qualis, que é dividida em Qualis A, B ou C, em nível internacional, nacional ou local".

Os periódicos Benjamin Constant e Espaço são classificados como CN Qualis C, em nível de circulação nacional enquanto

A Revista Educação Especial está indexada em 2 bases. Primeiramente foi obtida a indexação na base BEE/Inep, ainda com o título "Cadernos de Educação Especial", e posteriormente ela foi indexada na LATINDEX - Sistema Regional de Información em Línea para Revistas Científicas da América Latina, el Caribe, España y Portugal. O periódico consta também na Lista Qualis e é classificado como CN Qualis C, em nível de circulação nacional. 
A RBEE, que possui o maior número de indexações dentre os periódicos analisados, está acumulando indexações com o passar do tempo, fato que comprova a elevação da relevância científica do periódico. Em 2003, a partir do número 1 é obtida a indexação na base BEE/Inep; em 2004, a partir do número 2, o periódico é indexado em duas bases, a EDUBASE (FE/UNICAMP) e a CLASE - Citas Latinoamericanas en Ciencias Sociales y Humanidades (México, UNAM); ainda em 2004, a partir do número 3, a RBEE passa a ser indexada também na base Psicodoc - Colégio Oficial de Psicólogos de Madri (Espanha). Até o último fascículo pesquisado, portanto, a RBEE está indexada em quatro bases ( 2 nacionais e 2 internacionais). O periódico consta também na Lista Qualis, e é classificado como BN - Qualis B, em nível de circulação nacional.

Quanto à normalização das referências bibliográficas, observou-se que o periódico que atualmente apresenta-se em melhores condições é a Revista Educação Especial, que adota expressamente o sistema de normas da Associação Brasileira de Normas Técnicas - ABNT, particularmente a norma brasileira sobre elaboração de referências a NBR-6023, de agosto de 2002. Esta norma apresenta um conjunto padronizado de elementos descritivos retirados de um documento, o que permite a sua identificação individual. $O$ padrão adotado é seguido com maior rigor a partir do número 21, porém a qualidade da normalização reflui no exemplar posterior, voltando a melhorar no número 24 , a partir do qual o padrão ABNT é seguido com excelência. As incoerências encontradas antes do número 20 e nos números 22 e 23, tais como referências que seguem outras normas técnicas e aquelas que não seguem padrão algum. Vale salientar que os números publicados em 2005 estão devidamente em acordo com a NBR-6023, o que é um indício de que o problema foi detectado e corrigido com excelência.

A Benjamin Constant adota expressamente o sistema de normas da ABNT, porém não indica a norma específica, que seria a NBR-6023. O padrão é seguido com maior rigor a partir de 2002, porém até a última edição analisada são encontradas algumas incoerências entre as referências publicadas e os padrões estabelecidos pela ABNT. As incoerências encontradas são mínimas e restritas a algumas referências nas últimas edições, mas ainda sim, salientamos que podem prejudicar a identificação das fontes utilizadas para elaboração dos trabalhos. A utilização de exemplos de referências devidamente formatadas nas instruções sobre a elaboração das referências é um aspecto que poderia contribuir nesse sentido, se adotado.

Já na RBEE observou-se que o sistema de normas da ABNT de agosto de 2000 é adotado expressamente, porém, além de não indicar a norma específica, que seria a NBR-6023, a indicação do periódico está desatualizada, já que a norma técnica NBR-6023 mais recente data de agosto de 2002. O padrão adotado é seguido com maior rigor a partir de 2000, porém até a última edição analisada também são encontrados problemas entre as referências publicadas e os padrões estabelecidos pela ABNT. Os problemas encontrados são também mínimas, e assim como no periódico anterior podem prejudicar a identificação das fontes utilizadas para elaboração dos trabalhos. Merecem destaque os números 2 e 3 do volume 10 de 
2004, onde se encontram referências que seguem o padrão ISO e não o ABNT, conforme sugerido pela revista. A utilização de exemplos de referências devidamente formatadas nas instruções sobre a elaboração das referências é um aspecto que, como destacado anteriormente, contribui nesse sentido, e já é adotado de maneira satisfatória por essa revista. Cabe agora aos autores responsáveis pelos artigos submetidos adequar-se devidamente às normas propostas pelo periódico, assim como aos editores responsáveis pela revisão da normalização técnica verificarem devidamente os artigos recebidos e atualizarem a norma sugerida pelo periódico para padronização das referências.

A revista Espaço, por sua vez, não segue nenhuma norma. Observouse que, no número 22, é adotado expressamente o sistema de normas da ABNT, particularmente a NBR-6023 de agosto de 2002, e, antes disso, era adotada a versão de 1989 da mesma norma. O padrão adotado não é devidamente seguido até o último exemplar analisado, salvo alguns poucos artigos que apresentam referências bem formatadas ao longo da publicação. É possível encontrar desde referências que seguem outras normas técnicas até aquelas que não seguem padrão algum, fator capaz de prejudicar a identificação das fontes utilizadas para elaboração dos trabalhos. Como já apontado anteriormente, a utilização de exemplos de referências devidamente formatadas nas instruções sobre a elaboração das referências é um aspecto que poderia contribuir nesse sentido. Cabe, porém, salientar que a revista coloca que a exatidão das referências bibliográficas é de responsabilidade dos autores.

No verso da contracapa do periódico Benjamin Constant, assim como no site, encontram-se as instruções sobre a elaboração dos artigos. Constam aqui os critérios referentes ao envio dos artigos, formatação, conteúdo e normas adotadas para elaboração das referências de maneira clara e objetiva, o único item que fica implícito nessa área é a adoção do idioma português, que poderia ser apresentado de maneira mais clara. A revista aceita originais inéditos e trabalhos publicados anteriormente em periódicos estrangeiros, que estarão sujeitos à mesma avaliação de originais inéditos. O número de páginas não deve ultrapassar o limite de 10 laudas e o sumário encontra-se apresentado corretamente e somente em língua portuguesa. Vale lembrar que a ausência do sumário em outro idioma é um fator que dificulta a indexação do periódico em várias bases de dados.

O periódico RBEE apresenta tais instruções também ao final do periódico. Constam aqui os mesmos itens do periódico anterior, porém sem informações implícitas. O periódico aceita artigos inéditos e dá preferência aos trabalhos escritos no idioma português. O número de páginas não deve ultrapassar o limite de 25 laudas, estabelecido a partir do volume 8, número 2 de 2002, e o sumário é apresentado corretamente em língua portuguesa e inglesa, exceto nos volumes 2 , 3, 4 e 6, nos quais o sumário apresenta-se somente em português.

Também na Revista Educação Especial as informações referentes ao envio dos artigos, formatação, conteúdo e normas adotadas para elaboração das referências de maneira clara e objetiva encontram-se no final do periódico. $\mathrm{O}$ 
periódico aceita artigos inéditos e o idioma dos textos pode ser qualquer destes: português, espanhol, francês, inglês ou alemão. O número de páginas não é estipulado, ao invés disso é delimitado um intervalo de 2500 a 3500 palavras digitadas em espaço 1.5 para textos em geral e cerca de 1200 palavras para resenhas. E o sumário é apresentado corretamente em língua portuguesa e inglesa na versão impressa do periódico, já na versão online ele está disponível somente em português.

Já no periódico Espaço, as instruções sobre a elaboração dos artigos também se encontram no final do periódico. O periódico aceita artigos inéditos ou não, neste último caso a autorização para publicação depende de um aval do editor da publicação na qual o artigo foi primeiramente divulgado. Os textos podem ser escritos nos idiomas português ou espanhol. O número de páginas não deve ultrapassar o limite de 6 páginas com 30 linhas cada, e o sumário é apresentado somente em língua portuguesa e encontra-se na página de rosto.

Por fim, quanto aos critérios para avaliação dos artigos, observou-se a ausência desses indicadores expressos nos periódicos Espaço e Benjamin Constant, sendo, neste último, a única sugestão sobre o desenvolvimento do trabalho a abordagem de questões de interesse das pessoas portadoras de deficiência visual que englobam educação especial, reabilitação, preparação e encaminhamento profissional, oftalmologia e prevenção das causas da cegueira; o que parece ser um critério implícito. Observou-se também que existe a arbitragem por pares, sendo os artigos encaminhados à comissão editorial em ambos os periódicos, e na Benjamin Constant ainda está expresso que ela é formada por professores e técnicos da área de educação especial. Não há indicação de quantos profissionais compõem essa comissão em ambas as revistas. A RBEE apresenta de maneira satisfatória os critérios para avaliação dos trabalhos, além disso, o processo de avaliação de artigos da RBEE é detalhadamente discutido em um artigo de Manzini (2004) intitulado "Avaliação de Artigos da Revista Brasileira de Educação Especial". Na RBEE existe também a arbitragem por pares, discutida por Manzini no mesmo trabalho, sendo os artigos encaminhados primeiramente a dois pareceristas do Conselho Consultivo da ABPEE, que indicam a aceitação, a recusa ou as reformulações necessárias. Em caso de pareceres contrários a aceitação, o artigo é analisado pelos editores que permitem ou não a sua publicação baseada nas indicações dos pareceres. E enfim, a Revista Educação Especial também apresenta satisfatoriamente os critérios para avaliação dos artigos e a arbitragem por pares, sendo os artigos encaminhados primeiramente a dois pareceristas que indicam a aceitação, a recusa ou as reformulações necessárias. Em caso de pareceres contrários a aceitação, o artigo é analisado por um terceiro parecerista que permite ou não a sua publicação baseada nas indicações dos pareceres, um processo similar ao da $R B E E$.

\section{RECOMENDAÇÕES PARA ADEQUAÇÃO DOS PERIÓDICOS AOS CRITÉRIOS FORMAIS DE AVALIAÇÃO}

A partir dos resultados obtidos na pesquisa elencamos, a seguir, à guisa de recomendações à adequação dos periódicos aos critérios extrínsecos, os 
principais aspectos que podem ser aperfeiçoados pelos editores na direção de uma melhor situação frente às futuras avaliações.

a) as revistas Benjamim Constant e RBEE apresentam referências bibliográficas com problemas de normalização. A indicação de norma da ABNT desatualizada (de agosto de 2000) na RBEE mostra fragilidade por parte desse periódico em apresentar instruções adequadas quanto a este quesito, além de demonstrar falta de rigor na verificação destas referências;

b) a Revista Educação Especial apresentou constante presença de referências bibliográficas com problemas de normalização nos primeiros números analisados, embora tenha ocorrido uma acentuada melhoria nos últimos exemplares, demonstrando que o problema foi identificado e corrigido, o que contribui significativamente para a identificação dos materiais que serviram de suporte para a elaboração dos textos apresentados no periódico. Visando obter-se uma qualidade ainda melhor de apresentação das referências e também uma facilitação da análise dos pareceristas, poderiam ser acrescentados exemplos de aplicação da NBR-6023, uma atitude adotada apenas pela RBEE dentre os títulos analisados, agregando, desta forma, valor ao conteúdo informacional das instruções;

c) a revista Espaço apresenta-se em uma situação desconfortável nesse quesito, mostrando desatenção com a recuperação das fontes de informação utilizadas para elaboração dos trabalhos publicados ao atribuir aos autores a responsabilidade da adequação das referências. As instruções aos autores quanto à estrutura dos artigos estão devidamente expressas tanto na $R B E E$ quanto na Revista Educação Especial, não deixando lacunas para dúvidas. E o mesmo acontece com os critérios de avaliação dos artigos submetidos ao periódico, que, no caso da RBEE, contam ainda com o esclarecimento detalhado de Manzini (2004);

d) na Benjamin Constant a adoção do idioma português poderia deixar de ser implícita e a estrutura geral do artigo poderia estar presente em um só tópico, o que auxiliaria na uniformidade e apresentação dos artigos, tirando dúvidas ainda presentes nas instruções. No mesmo periódico e também no informativo Espaço, ainda poderia ser incluída a menção dos critérios para avaliação dos artigos de forma clara e objetiva, orientando os autores a respeito daquilo que será levado em consideração pelos pares no momento da avaliação. Sobre este aspecto Manzini (2003, p.16) discute o quão difícil é "manter a periodicidade de uma revista científica no Brasil, o que lhe confere o grau de periódico", alcançado com perfeição por todos os periódicos analisados, e a única melhoria a se destacar neste aspecto seria uma indicação explícita da periodicidade semestral na Revista Educação Especial;

e) o fato de tanto a Revista Educação Especial como a RBEE acumularem indexações no decorrer de suas edições demonstram que a relevância científica destes periódicos está em crescimento. Além disso, o número de idiomas aceitos na 
composição de trabalhos da Revista Educação Especial é outro fator que mostra a abertura da revista em receber contribuições de pesquisadores de outros países.

f) as publicações analisadas já estão consolidadas como meio de comunicação técnico-científica, no caso da Benjamin Constant e da revista Espaço, e científica, no caso da RBEE e Revista de Educação Especial, e fazem por merecer; a adequação a alguns aspectos formais seria mais um passo rumo ao futuro, pertinente para assegurar a qualidade e a confiabilidade destes periódicos, que têm sido bravamente trabalhadas e melhoradas ao longo do tempo.

\section{CONSIDERAÇÕES FINAIS}

A situação atual da comunicação científica quanto aos aspectos formais da apresentação de publicações periódicas brasileiras em Educação Especial tem melhorado com o passar do tempo, evoluindo assim como a própria Educação Especial enquanto área do conhecimento. Sendo assim, pode-se estabelecer o seguinte paralelo: a situação da comunicação científica periódica brasileira em Educação Especial tende a se adequar aos padrões formais vigentes conforme a própria Educação Especial consolidar-se como área do conhecimento, ao mesmo tempo em que essa adequação formal também contribui diretamente para a consolidação dos periódicos científicos desta área.

Com base nos resultados descritos neste artigo, outras avaliações podem ser conduzidas no que diz respeito aos seus aspectos de conteúdo dos periódicos. Nesse sentido, a área de Ciência da Informação pode contribuir com a melhoria, adequação e a consolidação dos periódicos nacionais, tanto em seus aspectos formais quanto de conteúdo.

Os resultados obtidos neste estudo revelam características importantes dos periódicos analisados e embora algumas delas já tenham sido atingidas com excelência outras ainda podem ser aprimoradas.

\section{REFERÊNCIAS}

ALONSO-GAMBOA, J. O. Selección de revistas lationamericanas en bases de dados: critérios utilizados em Clase y Periódica. Biblioteca Universitária: Revista de la Dirección General de las Bibliotecas de la UNAM, Nueva Época, v.6, n.1, p. 9-21, jul. 2003.

AMORIM, K. P. C. et al. A construção do conhecimento na odontologia: a produção científica em debate. Acta Cirúrgica Brasileira, São Paulo, v.20, supl. 1, p.8-11, 2005.

BARBALHO, C. R. S. Periódicos científicos em formato eletrônico: elementos para sua avaliação. In: CONGRESSO BRASILEIRO DE CIÊNCIAS DA COMUNICAÇÃO, 28., 2005, Rio de Janeiro. Disponível em: <http:/ / reposcom.portcom.intercom.org.br>. Acesso em: 13 dez. 2005.

BENJAMIN CONSTANT. Rio de Janeiro: IBCENTRO, v.11, n. 31, ago. 2005. 32p.

BOMFÁ, C. R. Z. et al. Análise de periódicos científicos com base na inteligência competitiva. In: CONFERÊNCIA IBEROAMERICANA DE PUBLICAÇÕES ELETRÔNICAS NO CONTEXTO DA INFORMAÇÃO CIENTÍFICA, 1., 2006, Brasília. Disponível em: <http:/ / www.portal.cid.unb.br/ CIPECCbr/viewpaper.php?id=9>. Acesso em: 10 set. 2006. 
BOMFÁ. C. R. Z. Revistas científicas de engenharia de produção: critérios e procedimentos para concepção em mídia digital. Dissertação (Mestrado) - Universidade Federal de Santa Catarina, Florianópolis, 2003.

BONINI, A. Qualis Letras/Lingüística: uma análise de seus fundamentos. Revista Brasileira de PósGraduação, Brasília, v.1, n.2, p.141-159, nov. 2004.

BRAGA, G. M.; OBERHOFER, C. A. Diretrizes para avaliação de periódicos científicos e técnicos brasileiros. Revista Latinoamericana de Documentación, Brasília, v.2, n.1, p.27-31, jun. 1982.

CAMPELLO, B. S., CAMPOS, C. M. Fontes de informação especializadas: características e utilização. 2.ed. Belo Horizonte: UFMG, 1993.

CASTRO, R. C. F.; FERREIRA, M. C. G.; VIDILI, A. L. Periódicos latino-americanos: avaliação das características formais e sua relação com a qualidade científica. Ciência da Informação, Brasília, v.25, n.3, 1996.

CENTRO DE EDUCAÇÃO - UFSM. S.d. Disponível em: <http://www.ufsm.br/ce/revista/>. Acesso em: 7 fev. 2006.

COSTA, A. L. F. Publicação e avaliação de periódicos científicos: paradoxos da classificação Qualis em Psicologia. Dissertação (Mestrado) - Universidade Federal do Rio Grande do Norte, Natal, 2006.

DIAS, C. G. de S. Periódicos na comunicação científica: produção e difusão de periódicos e panorama dos veículos brasileiros na área de Comunicação na base Qualis. Dissertação (Mestrado) Universidade Federal do Rio de Janeiro, Rio de Janeiro, 2006.

FACHIN, G. R.; HILLESHEIM, A. I. de A.; RADOS, G. J. V. Normas e padrões para os periódicos científicos on-line. In: SEMANA DE ENSINO, PESQUISA E EXTENSÃO DA UFSC, 5., 2005, Florianópolis. Disponível em: <http://www.sepex.ufsc.br/anais_5/trabalhos/450.html>. Acesso em: 10 set. 2006.

FACHIN, G. R.; HILLESHEIM, A. I. de A.; RADOS, G. J. V. Publicação periódica: revendo padrões de publicação e avaliação de artigos. In: COSTA, S. M. da S. et al (Eds.). Publicações eletrônicas no contexto da comunicação científica. Campo Grande/MS: Universidade para o Desenvolvimento do Estado e Região do Pantanal (UNIDERP), 2006. Disponível em: <http://portal.cid.unb.br/ CIPECCbr/>. Acesso em: 10 set. 2006.

FERREIRA, M. C. G.; KRZYZANOWSKI, R. F. Periódicos científicos: critérios de qualidade. Pesquisa Odontológica Brasileira, v.17, supl.1, p.43-8, 2003.

GOMES, S. P.; SANTOS, M. A. de L. C. Avaliação de um periódico na área de medicina tropical. Ciência da Informação, Brasília, v.30, n.2, p.91-100, maio/ago. 2001.

GRUSZYNSKI, A. C.; GOLIN, C. Periódicos científicos nos suportes impresso e eletrônico: apontamentos para um estudo-piloto na UFRGS. Revista de Economía Política de las Tecnologías de la Información y Comunicación, v.8, n.2, mayo/ago. 2006. Disponível em: <www.eptic.com.br>. Acesso em: 10 set. 2006.

GRUSZYNSKI, A. C.; SANSEVERINO, A. M. O periódico científico na área de humanidades: critérios de avaliação. In: CONGRESSO BRASILEIRO DE CIÊNCIAS DA COMUNICAÇÃO, 28., 2005, Rio de Janeiro. Anais... Rio de Janeiro, 2005.

HAYASHI, C. R. M. Presença da educação brasileira na base de dados Francis: uma abordagem bibliométrica. Dissertação (Mestrado em Educação) - Universidade Federal de São Carlos, São Carlos, 2004.

HAYASHI, M. C. P. I. et al. Avaliação de periódico científico na área de Educação Especial: aspectos formais da revista Benjamin Constant. Benjamin Constant, v.33, p.23-29, abr. 2006.

INSTITUTO BENJAMIN CONSTANT. Disponível em: <http://www.ibc.gov.br/>. Acesso em: 5 nov. 2005.

INSTITUTO NACIONAL DE EDUCAÇÃO DE SURDOS. Disponível em: < http:/ / www.ines.org.br/ >.Acesso em: 23 mar. 2006.

JACON, M. do C. M. Base Qualis: uso e qualidade dos periódicos científicos no Programa de PósGraduação em Psicologia da Pontifícia Universidade Católica de Campinas (1997-2002). Dissertação (Mestrado) - Pontifica Universidade Católica de Campinas, Campinas, 2006. 
KRZYZANOWSKI, R. F.; FERREIRA, M. C. G. Avaliação de periódicos científicos e técnicos brasileiros. Ciência da Informação, Brasília, v.27, n.5, p.165-175, maio/ago. 1998.

LÓPES-ORNELAS, M.; CORDERO-ARROYO, G.; BACKHOFF-ESCUDERO, E. Measuring the quality of electronic journals. The Electronic Journal of Information Systems Evaluation, v.8, n.2, p.133142, 2005.

LÓPEZ-CÓZAR, E. D. Evaluación del grado de ajuste de las revistas españolas de ciencias de la salud a las normas internacionales de presentación de publicaciones periódicas. Revista Española de Salud Pública, v.71, n.6, p.531-56, nov./dec. 1997.

MANZINI, E. J. Análise de artigos da Revista Brasileira e Educação Especial (1992-2002). Revista Brasileira de Educação Especial, Marília, v.9, n.1, p.13-24, jan./jun. 2003.

MANZINI, E. J. Avaliação de artigos da Revista Brasileira e Educação Especial. Revista Brasileira de Educação Especial, Marília, v.10, n.3, p.273-286, set./dez. 2004.

MARCUSCHI, L. A. Revistas brasileiras em letras e lingüística. DELTA: documentação de Estudos em Lingüística teórica e aplicada, São Paulo, v.17, n.esp., p.83-120, 2001.

MAYOR, F. Oppening Adress. Joint ICSU Press/Unesco Expert Conference on Electronic Publishing in Science, Paris, p.19-23, feb. 1996. Disponível em <http://www.library.uiuc.edu/icsu/ dgspeech.htm>. Acesso em: 07 ago. 2006.

MEADOWS, A. J. A comunicação científica. Brasília: Briquet de Lemos, 1999.

MIRANDA, D. B.; PEREIRA, M. de N. F. O periódico científico como veículo de comunicação: uma revisão de literatura. Ciência da Informação, Brasília, v.25, n.3, p.375-382, set./ dez.1996.

MUELLER, S. O círculo vicioso que prende os periódicos nacionais. DataGramaZero - Revista de Ciência da Informação, n.zero, dez. 1999. Disponível em: <http://www.dgz.org.br/dez99/ F_I_art.htm>. Acesso em: 10 set. 2006.

OLIVEIRA, E. B. Produção científica nacional na área de geociências: análise de critérios de editoração, difusão e indexação em bases de dados. Ciência da Informação, Brasília, v.34, n.2, p.34-42, maio/ago. 2005.

OLIVEIRA, E. C. P. O apoio governamental às publicações periódicas científicas: o programa de apoio às revistas do CNPq e da FINEP. Dissertação (Mestrado) - Universidade Federal do Rio de Janeiro, Rio de Janeiro, 1989.

PEREIRA, J. C. R.. Revista de Saúde Pública: quarenta anos da produção científica no Brasil. Revista de Saúde Pública, v.40, n.esp., p.148-159, ago. 2006.

PESSANHA, C. Critérios editoriais de avaliação científica: notas para discussão. Ciência da Informação, Brasília, v.27, n.2, p.226-29, maio/ago. 1998.

PINHEIRO, L. V. R. et al. Ciência da Informação: 32 anos (1972-2004) no caminho da história e horizontes de um periódico científico. Ciência da Informação, Brasília, v.34, n.3, p.23-75, set./dez. 2005.

REVISTA BRASILEIRA DE EDUCAÇÃO ESPECIAL. Marília: ABPEE/FFC-Unesp-Publicações, $1992-$ . Quadrimestral. ISSN 1413-6538. Consultado até o v.11, n.2.

REVISTA EDUCAÇÃO ESPECIAL. Santa Maria, RS: UFSM, n.24, 2004. 115p. ISSN 0103-0000.

RÍOS-ORTEGA, J. Normalización de revistas científicas mexicanas: campo de investigación y aportación. Biblioteca Universitária. Revista de la Dirección General de las Bibliotecas de la UNAM, Nueva Época, v.3, n.2, p.85-91, jul./dic. 2000.

RODRIGUES, M. E.F.; LIMA, M. H. T. de F.; OLIVEIRA-GARCIA, M. J. de. A normalização no contexto da comunicação científica. Perspectivas em Ciência da Informação, Belo Horizonte, v.3, n.2, p.147-156, jul./dez.1998.

ROMANCINI, R. Periódicos brasileiros em Comunicação: histórico e análise preliminar. Verso e Reverso - Revista da Comunicação, v.18, n.39, 2004.

SCHULTZE, S. Características de periódicos científicos produzidos por editoras universitárias brasileira. Informação e Sociedade, João Pessoa, v.15, n.2, 2005. Disponível em: <http:// periodicos.ufpb.br/ojs2/index.php/ies/article/view/36>. Acesso em: set. 2006. 
SCHWARTZMAN, S. A política brasileira de publicações científicas e técnicas: reflexões. Revista Brasileira de Tecnologia, Brasília, v.15, n. 3, p. 25-32, 1984. Disponível em: <http:// www.schwartzman.org.br/simon/pol_pub.htm>. Acesso em: dez. 2006.

SILVA, M. R. Análise bibliométrica da produção científica docente do Programa de Pós-Graduação em Educação Especial / UFSCar: 1998-2003. Dissertação (Mestrado em Educação Especial) - Universidade Federal de São Carlos, São Carlos, 2004.

SOARES, A. B. A et al. Psicologia divulgada através de periódicos científicos indexados e através de revistas de grande circulação no Brasil: um estudo preliminar. Psicologia para América Latina, n.7, ago. 2006. Disponível em: <http:// psicolatina.org/Siete/index.html>. Acesso em: 11 nov. 2006.

SOUZA, E. P. S. Publicação de revistas científicas na internet. Brazilian Journal of Cardiovascular Surgery, São José do Rio Preto, v.21, n.1, p.24-28, 2006.

SOUZA, L. K.; GAUER, G.; HUTZ, C. S. Publicações em psicologia do desenvolvimento em dois periódicos nacionais na década de 1990. Psico-USF, Bragança Paulista, v.9, n.1, p.49-57, jan./jun. 2004.

SOUZA, M. F. S.; VIDOTTI, S. A. B. G.; FORESTI, M. C. P. P. Critérios de qualidade em artigos e periódicos científicos: da mídia impressa à eletrônica. Transinformação, Campinas, v.16, n.1, p.71-89, jan.-abr. 2004.

STUMPF, I. R. C. Avaliação das revistas de Comunicação pela comunidade acadêmica da área. Em Questão, Porto Alegre, v.9, n.1, p.25-38, jan./jun.2003.

STUMPF, I. R. C. Reflexões sobre as revistas brasileiras. InTexto, Porto Alegre, v.1, n.3, 1998.

TRZESNIAK, P. A avaliação de revistas eletrônicas para órgãos de fomento: respondendo ao desafio. In: COSTA, S. M. da S. et al. (Eds.). Publicações eletrônicas no contexto da comunicação científica. Campo Grande/MS: Universidade para o Desenvolvimento do Estado e Região do Pantanal (UNIDERP), 2006a. Disponível em: <http:/ / portal.cid.unb.br/CIPECCbr/viewabstract.php?id=26>. Acesso em: 10 set. 2006.

TRZESNIAK, P. As dimensões da qualidade dos periódicos científicos e sua presença em um instrumento da área da educação. Revista Brasileira de Educação, v.11, n.32, p.346-361, maio/ago.2006b.

VALÉRIO, P. M. Avaliação do Programa Setorial de Publicações em Ciência e Tecnologia: as revistas científicas financiadas pela FINEP. Dissertação (Mestrado) - Universidade Federal do Rio de Janeiro, Rio de Janeiro, 1991.

VALÉRIO, P. M. O periódico científico. In: Curso de Atualização sobre Avaliação do Trabalho Científico. Petrópolis: ABEC, 2005. Disponível em: <http:/ /www.lncc.br/abec/eventos.php>. Acesso em: dez. 2006.

VALÉRIO, P. M. Espelho da ciência: avaliação do programa setorial de publicações em ciência e tecnologia da FINEP. Brasília: FINEP/IBICT, 1994.

YAMAMOTO, O. H. Vale a pena avaliar periódicos científicos? Estudos de Psicologia (Natal), Natal, v.6, n.2, p.129-131, jul./dez.2001.

YAMAMOTO, O. H.; SOUZA, C. C.; YAMAMOTO, M. E. A produção científica na psicologia: uma análise dos periódicos brasileiros no período 1990-1997. Psicologia: Reflexão e Crítica, v.12, n.2, p.549565, 1999.

YAMAMOTO, O. H. et al. Avaliação de periódicos brasileiros na área da psicologia. Ciência da Informação, Brasília, v.31, n.2, p.163-177, 2002.

ZIMAN, J. Conhecimento público. Belo Horizonte: Itatiaia, 1979.

Recebido em 24/08/2006

Reformulado em 28/12/2006

Aprovado em 30/12/2007 